\title{
Aspectos epistemológicos subjacentes a erros individuais frequentes no ensino institucionalizado
}

Epistemological aspects underlying frequent individual errors in institutionalized teaching

\author{
Werventon dos Santos Miranda ${ }^{1}$ \\ Luciana de Nazaré Farias ${ }^{2}$ \\ Silvio Carlos Ferreira Pereira Filho ${ }^{3}$
}

\section{Resumo}

Neste artigo procuramos discutir as questões epistemológicas que estão presentes nas causas dos erros individuais no processo de ensino e aprendizagem das disciplinas escolares, mais precisamente relacionados aos conhecimentos da Matemática, Física e Biologia; procuramos trazer inicialmente uma noção histórica e conceitual dos principais termos que envolvem essa temática como erro e epistemologia; buscamos evidenciar a luz de Bachelard e Vygotsky, além de outros que trazem questões especificas nas Ciências em destaques os elementos que subjazem os erros que manifestamos na caminhada escolar; e finalizamos expressando, nas considerações finais, nossa visão do erro como ferramenta da ação pedagógica para contribuir com os alunos na perspectiva de superação a fim de que o objetivo do processo educativo seja alcançado - a aprendizagem.

Palavras chave: conhecimentos; erros individuais; aspectos subjacentes.

\section{Abstract}

In this paper we discuss the epistemological issues that are present in the causes of individual errors in the teaching and learning of school subjects, specifically related to the knowledge of Mathematics, Physics and Biology; initially we seek to bring a historical and conceptual notion of the main terms involving this issue such as error and epistemology; we seek to make evident in light of Bachelard and Vygotsky, and others who bring specific issues in these Sciences, the elements that underlie the errors we make in the school journey, and finally we express, in the concluding remarks, our view of error as a tool of pedagogical action to help students with the aim of overcoming so that the goal of the educational process is achieved - learning.

Keywords: knowledge; individual errors; underlying aspects.

\footnotetext{
${ }^{1}$ Universidade Federal do Pará | wesamiranda@yahoo.com.br

${ }^{2}$ Universidade Federal do Pará | lubiologia2003@yahoo.com.br

3 Universidade Federal do Pará | silviocfilho@gmail.com
} 


\section{Introdução}

O erro é um componente constituinte da ação humana, seja por que nossa ação busca um produto final baseado em um modelo, seja por que, embora não haja um modelo a ser seguido, o resultado obtido não satisfaz nossa intenção pré-determinada como ideal; o que geralmente nos faz classificar como erro a ação mal sucedida.

No contexto escolar a presença do erro é constante, embora indesejável, principalmente no processo de ensino e aprendizagem; neste contexto o erro se faz presente quando o aprendiz age e sua ação se desvia do padrão, ou seja, não é validada pela ótica escolar.

Assim, ninguém que discute e/ou vive o processo educativo é indiferente ao erro; por isso, para uns ele é indicador de fracasso, para outros, ponto de partida para uma ação pedagógica qualificada; por também acreditarmos na possibilidade e potencialidade do uso do erro como ferramenta pedagógica, nos propomos iniciar neste trabalho uma busca teórica das relações presentes entre a existência dos erros individuais que se evidenciam durante o processo de aprendizagem de Ciências e as questões epistemológicas que podem favorecer o aparecimento desses erros, para entendermos melhor o surgimento destes no processo educativo.

Antes de prosseguirmos no desenvolvimento do tema é relevante esclarecer a especificação de erros individuais, visto que o comum é nos referimos a erros; esta adjetivação deriva do fato de já ter sido estabelecido, por Miranda (2007) ${ }^{4}$ no âmbito do ensino da Matemática, a existência de 'obstáculo didático coletivo'5 que, pela própria definição adotada pelo referido autor em sua pesquisa, evidencia a existência de erros coletivos; a qual admitimos ser validadas também para as demais disciplinas e nos permite pensar em erros individuais e as questões epistemológicas que causam esses erros, tendo em vista que as pesquisas cujo objeto de estudo é a problemática do erro no contexto escolar não as consideram ou as deixam subentendidas nos seus resultados.

\section{Panorama}

Dentro do processo de ensino-aprendizagem, há pelo menos um século o erro vem despertando o interesse dos pesquisadores da educação, cujas abordagens variam desde uma orientação behaviorista prendendo-se na "conduta observável", ou seja, no erro em si até a predominância do enfoque relativo ao processamento da informação que vigorou a partir da década de 50. Em relação a esse movimento de mudança do enfoque, Cury (1995; 40) nos informa que em ambas as abordagens a análise do erro de matemática se restringia a diagnóstico e reparo, caracterizando, assim, uma visão absolutista da Matemática. Tal

\footnotetext{
4 Miranda (2007), dissertação com o título Erros e Obstáculos: Os conteúdos Matemáticos do Ensino Fundamental no Processo de Avaliação

5 Considera-se como parâmetro para análise de diferenciação entre o erro em si ou "erro passageiro" e o erro que indica um obstáculo didático, as questões que apresentam um quantitativo de erros semelhantes com índice de $20 \%$ ou mais em relação ao total de estudantes da turma.
} 
visão se verificou também no âmbito do ensino universitário onde "de uma maneira geral, os professores participantes dessa pesquisa parecem assumir uma concepção absolutista da Matemática, vendo-a como o domínio do conhecimento incontestável e verdades absolutas".

Neste contexto, observando a literatura sobre o erro no âmbito escolar podemos constatar que muitos pesquisadores tem se dedicado ao tema, tais como: Cury (1995), Pinto (2000), De La Torre (1994) In Pinto (2000), Gotino, Batanero \& Font In Pochulu (2005) e vários outros nos mostram que ao longo dos anos, os diferentes estudos sobre o erro, foram modificando tanto as abordagens como a perspectiva de seu "tratamento" no âmbito pedagógico; assim, o erro passa de elemento inadequado e 'mal quisto' no contexto de aprendizagem para um elemento constituinte do processo ensino-aprendizagem que pode abrir portas para um novo conhecimento ou dar oportunidade à revisão e ao aperfeiçoamento daquilo que já é conhecido.

Também se faz necessário falarmos, mesmo que resumidamente, do que vem a ser o termo EPISTEMOLÓGICO; esse termo se refere à preocupação com a metodologia de construção e sistematização do conhecimento científico, a coerência de sua argumentação e a relação com "seus produtos intelectuais" conforme as palavras de Japiassu (1934; p.17).

Para Bachelard (1996; p. 17)6, a expressão 'obstáculo epistemológico' faz referência às dificuldades da Ciência ao longo da História em que um conhecimento que faz resistência a um conhecimento novo; afirmando ainda que "é no âmago do próprio ato de conhecer que aparecem, por uma espécie de imperativo formal, lentidões e conflitos. É aí que mostraremos causas de inércia as quais daremos o nome de obstáculo epistemológico"; ou seja, a expressão foi usada pelo autor para nomear os fatores que, na sua concepção, impediam ou dificultavam o estabelecimento e desenvolvimento de um conceito científico ao longo da história, bem como a sistematização do conhecimento produzido dentro de cada ciência.

Os argumentos introdutórios apresentados não se restringem a Matemática; pois no ensino de Física, podemos considerar dois principais aspectos epistemológicos subjacentes a erros individuais. Estes aspectos estão relacionados entre si devido à concepção sobre o conhecimento e seu ensino. Queremos aqui destacar a existência desses aspectos e suas consequências no processo educativo.

Um dos aspectos é o efeito descritivo, a transmissão de conteúdos conceituais e procedimentais, sem espaço para discussão ou interação entre estudante e professor. Este aspecto nos remete à ideia de que o conhecimento é pré-existente, cabendo aos cientistas apenas descobri-lo, ou seja, não é passível de construção humana e subjetiva; assim, o conhecimento é [tido] visto como objetivo, correto e verdadeiro, de modo que é necessário transmiti-lo tal qual foi descoberto, sem dar lugar a discussões ou subjetividades. O outro aspecto a ser considerado, sem estar dissociado ou hierarquizado do já mencionado, advém do fato de que, para muitos, o estudante é visto como sujeito incapaz de construir conhecimento algum, pois ele não apresenta nenhuma perspectiva científica que possa ser aproveitada para o ensino.

Assim sendo, o estudante deve apenas aceitar incondicionalmente, absorver, aquilo que the é ensinado. Esses dois aspectos promovem um tipo de ensino que está distante da

6 A primeira edição foi publicada em 1938. 
possibilidade de compreensão pelos estudantes, pois é praticado fora de qualquer contexto significativo para eles, seja por falta de uma ligação com seus cotidianos, seja por estar além de suas estruturas cognitivas. Este tipo de conhecimento sem significado tem grande possibilidade de incompreensão parcial ou completa, o que acarreta diversos erros no momento de sua avaliação de aprendizagem.

Sem desconsiderar as peculiaridades da Biologia, observamos que o seu ensino não é diferente, pois nem sempre se tem permitido que o estudante se aproprie dos conhecimentos científicos de modo a compreendê-los, questioná-los e utilizá-los como instrumento do pensamento que extrapolam situações de ensino e aprendizagem eminentemente escolares. (MORTIMER, 1996). Tais repercussões no ensino de Biologia nos permitem por inferência relacioná-los a questão do erro, pois se o aluno não compreende, não questiona ou não utiliza os conhecimentos científicos na organização do pensamento, a nosso ver não aprende Biologia, ou ainda, os conhecimentos apresentados aos alunos acaba por induzi-los a erros; os quais consideramos decorrer principalmente por dois obstáculos: epistemológicos e linguísticos, quanto aos obstáculos epistemológicos, observamos que nos livros didáticos de biologia, ao focarem, por exemplo, a história da ciência no ensino da Biologia, segundo Martins (1998; 18), destaca que devemos ser vigilantes na nossa maneira de ensinar, na qual mostramos nossa concepção de Ciência, pois neste processo é recomendável evitar que:

Se adote uma visão ingênua (ou arrogante) de ciência, como sendo "a verdade" ou "aquilo que foi provado", alguma coisa de eterno e imutável, construída por gênios que nunca cometem erros e eventualmente alguns imbecis que fazem tudo errado. Por outro lado, deve impedir a adoção de uma visão anti-cientificista de que todo conhecimento nada mais é do que mera opinião.

Com relação às teorias Evolutivas, por exemplo, é comum nos livros didáticos de Biologia do Ensino Médio de distribuição Nacional, Lamarck seja um pesquisador apontado pelos autores como eminentemente errado, (MARTINS, 1998; p.19) destaca o seguinte trecho de um livro didático: "Lamarck propôs sua doutrina na Philosophie zoologique, publicada em 1809. Seu maior mérito foi provocar debates e pesquisas. Estudos posteriores vieram provar que o Lamarckismo está irremediavelmente errado [...]".

Quanto aos aspectos linguísticos, destacamos que os termos biológicos são escritos em Latim ou uma versão latinizada, desde o século XVII. Exemplificamos, com a nomenclatura binominal dos seres vivos de Carl von Linné: Abelha - Apis mellifera scutellata, Lagartixa Phyllopezus pollicaris, Lambari - Astyanax fasciatus. Tradicionalmente, a classificação de animais segue o Código Internacional de Nomenclatura Zoológica. No estudo das regras de nomenclatura Zoológica (ou Botânica), observamos que a não familiaridade de alunos e professores com os termos, bem como o número elevado de exceções da nomenclatura científica constituem obstáculos linguísticos. Muitos termos em Biologia são usualmente divulgados por siglas, sem que se tomem conhecimento de seu significado, exemplifico: DNA (ácido desoxirribonucléico), ATP (adenosina trifosfato) e outros mais. 


\section{Aspectos subjacentes}

Olhando para o processo de ensino-aprendizagem institucionalizado (processo escolar) no qual o objeto de estudo é posto para o conjunto de aprendizes ao mesmo tempo e de mesma forma em sala de aula, que elementos subjacentes neste processo contribuem para que parte deste grupo acerte e outra erre?

Corrobora com a busca de uma resposta a observação de Bondía (2002; p. 27), registrado no texto Notas sobre a experiência e o saber de experiência, o autor após fazer um significativo estudo da palavra experiência em alguns idiomas, conclui que:

Se a experiência não é o que acontece, mas o que nos acontece, duas pessoas, ainda que enfrentem o mesmo acontecimento, não fazem a mesma experiência. O acontecimento é comum, mas a experiência é para cada qual sua, singular e de alguma maneira impossível de ser repetida. $O$ saber da experiência é um saber que não pode separar-se do indivíduo concreto em quem encarna.

O texto em destaque realça a evidencia de que o ato de ensinar pode ser coletivo no sentido de que nos propomos a compartilhar nossos conhecimentos com outrem em um mesmo momento, porém há elementos que torna esse compartilhamento um processo diferenciado; como consequência disso, temos que ao tentar aferir o resultado do que chamamos de ensino encontramos duas diferentes manifestação desse ensino e que chamamos de aprendizagem: 1) os que acertam e aos quais imputamos como os que aprenderam e 2) os que erram, aos quais associamos a ideia de não aprendizagem.

Conjecturamos que interrogações semelhantes à expressa no primeiro parágrafo dessa secção tenham levado muitos pesquisadores a estudar os erros no contexto escolar; na obra de Pinto (2000), por exemplo, observamos que os estudos do erro de matemática receberam influências da psicologia e da pedagogia na orientação da análise do tema; as contribuições desta autora trazem três alternativas teóricas aplicáveis ao estudo do erro no processo de ensino-aprendizagem, que podem auxiliar na compreensão das relações de sua natureza, quais sejam:

A perspectiva psicogenética, baseada nas contribuições dos estudos de Piaget sobre o desenvolvimento e a complexidade das estruturas de nosso pensamento bem como sua estreita relação destes com o "amadurecimento" genético. A perspectiva epistemológica, advinda da coordenação das ideias de Bachelard sobre o desenvolvimento da ciência e de Brousseau no contexto do ensino da matemática. A perspectiva sociológica traz em si o antagonismo de 'classes' representado no binômio sucesso/fracasso escolar; essa corrente busca diminuir os antagonismos sociais, ou pelo menos não reproduzi-los no âmbito escolar, e nessa perspectiva, "o erro do aluno deve possibilitar a eliminação de toda ordem de coerção e desvalia pelo fracasso em matemática"; sem que isso nos leve ao outro extremo, que seria fazer apologia do erro como diz Luckesi (2002).

O histórico das pesquisas e as conclusões que as mesmas nos permitem chegar, tem revelado nos últimos anos que há regularidade de ideias dos aprendizes ao produzirem 'respostas erradas' durante o processo de ensino-aprendizagem, o qual nos possibilita classificá-las como Obstáculo Didático cuja definição de Pais (2001) sintetiza como "conhecimentos que se encontram relativamente estabilizados no plano intelectual e que podem dificultar a evolução da aprendizagem do saber escolar" e dentro desta linha, já há pesquisas que demonstram que os erros que caracterizam os obstáculos didáticos podem 
ser de origem: linguística (ALMOULOUD, 2006) - os quais se referem às barreiras que impedem a compreensão do conteúdo em função da não habilidade no uso da língua materna por parte de aprendizes e até professores que utilizam os mesmos significantes (representações de um objeto ou ideia) com diferentes significados (conceitos a que as representações nos remetem); emocional - caracterizada pela alteração da nossa estabilidade emocional, expressa aos pares - atenção/desatenção, prazer/desprazer, responsabilidade/necessidade de desenvolver corretamente uma questão - que diante de determinadas tarefas e disciplinas, pode induzir ao erro e vice-versa, pois "Um obstáculo emocional induz ao erro e, configurando-se o erro, este desencadeia emoções como: frustrações de expectativas, angústias, raiva, sentimento de inferioridade, entre outras" (GUSMÃO, 2000; p. 63).

Vamos, ousada e paradoxalmente, trazer para nossa reflexão o pesquisador Vygotsky e sua teoria Sócio-Interacionista (ou Sócio-Histórica) na qual o ser humano tem seu desenvolvimento psíquico como resultado da interação social, com a finalidade de buscar mais elementos para continuar dialogando sobre os erros individuais; aportando-nos nas pesquisas deste autor e seus colaboradores podemos afirmar que o aprendizado se expressa, entre outras coisas, pela formação de conceito que é fruto da interação social mediada pela linguagem; sendo que esta é a faculdade de expressão e comunicação que faz uso de um código composto por um conjunto de signos convencionados unindo significante e significado.

Mas sendo a linguagem uma faculdade de expressão e comunicação, tal faculdade só ocorre na interação entre indivíduos; isto torna a linguagem um elemento integrante da cultura que Gómez (2001) define como:

O conjunto de significados, expectativas e comportamentos compartilhado por um determinado grupo social, o qual facilita e ordena, limita e potencia os intercâmbios sociais, as produções simbólicas e materiais e as realizações individuais e coletivas dentro de um marco espacial e temporal determinado. (p. 17)

Além disso, devemos nos alertar que a Matemática não é somente uma disciplina curricular como também uma linguagem científica e, segundo Oliveira (2007) referendada em Machado (apud Smole, 2000), "como uma linguagem cientifica que é, não possui oralidade própria: está totalmente voltada para a escrita". Assim, julgamos que outro aspecto epistemológico subjacente a existência dos erros dos alunos pode estar na conjugação da linguagem materna com a linguagem matemática, mais precisamente no compartilhamento de significante e significado, onde o mesmo significante pode ter significados diferentes (tanto na mesma língua ou no intercambio entre as línguas) para professores e alunos, gerando "deformações" nas explicações, definições, procedimentos e conceitos expressos e suas respectivas aplicações; são essas 'deformações' que chamamos de erros.

A discussão é valida para o ensino de Física, onde os significados não podem ser negociados em hipótese alguma; pois na concepção dominante sobre o ensino desta ciência, é necessário se manter o rigor da linguagem para que o conhecimento possa ser transmitido de forma correta. Assim também se configura o erro dos estudantes quando eles não se apropriam, ou melhor, não reproduzem a linguagem científica como Ihes foi ensinada, não importando se eles compreenderam ou não os termos desta linguagem. 
Um exemplo interessante desta rigidez da linguagem se evidencia no estudo de movimentos através da Mecânica. Embora os movimentos com velocidade linear constante, organizados didaticamente na Cinemática, possam ocorrer em qualquer trajetória, desde que sejam estudados no âmbito de uma única dimensão, os professores insistem em distinguir o Movimento Retilíneo Uniforme (MRU) de qualquer outro movimento uniforme (como o Movimento Circular Uniforme). Desse modo, em suas avaliações, tais professores cobram de seus alunos que classifiquem vários movimentos como MRU ou não-MRU. Os diversos mecanismos mnemônicos criados pelos estudantes para memorizar os modelos que devem ser reproduzidos também mostram a rigidez dessa linguagem, como a famosa fórmula do sorvete, $s=s_{0}+v \cdot t$, onde $s_{0}$ e $s$ representam as posições do corpo em movimento no instante em que inicia-se a observação desse movimento e em um instante qualquer que pode ser escolhido aleatoriamente. Para a maioria dos estudantes, sujeitos a abordagem de ensino de transmissão do conteúdo, mudar os símbolos da posição para outra variável, como $x$, por exemplo, é tornar esta fórmula praticamente irreconhecível.

Outra semelhança envolvendo o ensino da Física e Matemática pode ser vista no aspecto da linguagem, desta vez, do ponto de vista posicional; pois a fórmula $s=s_{0}+v \cdot t$, que representa algebricamente o MRU, é uma função linear de $1^{\circ}$ grau que a Matemática representa por $y=a \cdot x+b$ e muita das vezes os estudantes não fazem a relação de que na fórmula utilizada no estudo e representação deste movimente: $s$ corresponde a $y, s_{0}$ corresponde $a b$ e $v \cdot t$ corresponde $a \boldsymbol{a} \cdot \boldsymbol{x}$. Isto acontece tanto em função da mudança das letras representativas quanto pela alteração na ordem dos termos, pois "a formula geral da equação da função linear" dada por $y=a \cdot x+b$ estaria escrita fora da ordem comumente vista, com $y=b+a \cdot x$, talvez muitos de nós professores compartilhe com os alunos essa mesma dificuldade de associação em função da não compreensão da linguagem simbólica.

Tomando como referência o ensino de Biologia, pesquisas sobre a formação de conceitos têm demonstrado que estudantes da educação básica apresentam dificuldades na construção do pensamento biológico. Tais pesquisas revelam, por exemplo, que a maioria dos estudantes desse nível de ensino apresentam ideias sincréticas, portanto, pouco definida sobre célula, confundindo este conceito com os de átomo, molécula e tecido (BASTOS, 1992). Para muitos, a relação entre seres vivos e células existe apenas nos seres humanos (SILVEIRA, 2003).

Nossa experiência docente na educação básica nos permite afirmar que, os erros dos estudantes nas avaliações de Biologia geralmente estavam relacionados aos obstáculos linguísticos, evidenciando a dificuldade em se relacionar os conceitos científicos com a realidade vivenciada por eles, hoje temos mais clareza disso. Por exemplo, ao abordarmos a temática "vitaminas" no ensino fundamental, buscar explicitar que "vitamina C" é o "ácido ascórbico", assim com as demais vitaminas e suas relações com as denominações científicas era conflituoso, acredito analisando criticamente que a metodologia tradicional de ensino abordada não propiciava aprendizagem significativa dos alunos.

Vale ressaltar que o modelo de educação institucionalizada predominante em nosso país é a de turmas presenciais, com aulas expositivas cuja linguagem, oral ou escrita, é a principal ferramenta de interlocução e o acompanhamento da aprendizagem revela dois grupos de aprendizes: os que acertam e os que erram. Cremos que nas turmas na modalidade à distância isto também acontece com outras intensidades e que não temos conhecimento suficiente para discutir ou generalizar as inferências que aqui ensaiamos; outra coisa a considerar é o fato de que todos os que estão hoje inseridos na educação à 
distância já passaram pelas turmas presenciais, fato que faz nossa discussão atingir a todos, pelo menos em relação ao inicio da escolaridade.

Concentrando nossas atenções para o grupo dos que erram, dentro da modalidade presencial, podemos subdividi-los entre os que têm erros individuais (erros cuja característica - conceitual ou processual - é de serem cometidos por um mesmo indivíduo em diferentes situações, desde que um mesmo conceito ou procedimento seja requerido) e os que têm erros coletivos (erros cuja característica - conceitual ou processual - se assemelham em um expressivo número de indivíduos), conforme a definição dada por Miranda (2007) a qual nos referimos anteriormente.

Sendo o objetivo discutir as questões pertinentes aos erros individuais e recorrendo ao breve panorama teórico até aqui realizado, mesmo considerando-o insuficiente para uma conclusão formal, podemos, por inferência, relacionar como aspectos epistemológicos subjacentes aos erros individuais os que se vinculam mais diretamente a questões psicogenéticas, emocionais e linguísticas e as demais aqui abordadas (epistemológicas, sociológicas e didáticas) estariam mais ligadas ao aparecimento dos erros coletivos, sem, contudo, o fato de haver predominância de influência das primeiras questões sobre os erros individuais exclui-las de serem subjacentes aos erros coletivos; sendo recíproca a afirmação para os aspectos que predominam sobre os últimos em relação aos primeiros.

Um bom exemplo de não excludencia a que fizemos referência anteriormente está no aspecto linguístico; porém, antes de evidenciá-lo é interessante observar as considerações de Moysés (1997; p. 39) sobre 'Significado e Sentido' quando nos diz que:

Ao assimilar o significado de uma palavra o homem está dominando a experiência social. No entanto, essa depende da individualidade de cada um. É essa individualidade que faz com que uma mesma palavra conserve, ao mesmo tempo, um significado - desenvolvido historicamente - compartilhado por diferentes e um sentido todo próprio e pessoal de cada um.

O trecho em destaque nos permite inferir que o aspecto linguístico é epistemologicamente subjacente tanto aos erros individuais quanto aos erros coletivos, tornando-a um elemento comum entre as duas "classificações" ou como dito no início deste texto - "adjetivação" - do erro; questão que sugere uma discussão em outra oportunidade.

Pelo que foi possível abstrair e interligar da literatura visitada até o momento, podemos considerar que um estudo mais aprofundado das teorias existentes sobre o processo de ensino e aprendizagem juntamente com as que se dedicam a explicitar as causas e/ou consequências do erro durante a caminhada escolar, como é nosso propósito, permitirá definir balizes teóricas para separar, didaticamente dizendo, os aspectos epistemológicos subjacentes aos erros individuais frequentes no ensino fundamental, especialmente nas disciplinas de Matemática, Física e Biologia que foram aqui destacadas. 


\section{Considerações Finais}

Neste texto, tivemos por intuito reunir algumas pesquisas sobre o erro juntamente com outras teorias que se ocupam do fenômeno educativo ou ainda as conclusões obtidas em outros campos que podem ser estendidas à educação, tais estudos têm pontos comuns ou de interligações, os quais, a nosso ver, possibilitam ampliar o conhecimento que temos a cerca das causas do erro não apenas no contraste em relação ao concebido como certo; mas a ter em consideração outros elementos desencadeadores de erros que não se restringem a capacidade de aprender.

Assim, as pesquisas sobre os erros dos alunos produzidas ao longo dos anos, tanto no âmbito geral quanto especificamente em cada área de conhecimento disciplinar, nos permitem não apenas considerá-lo como ferramenta da ação pedagógica, mas nos alertam para as muitas fontes de sua existência e ao mesmo tempo em que buscam contribuir com nosso fazer profissional, aumenta consideravelmente nossa responsabilidade; visto que ao nos tornar cientes destas possíveis causas de erros e suas subjacências, nos impõe a necessidade de saber reconhecê-las e nortear nossa ação para contribuir com os alunos na perspectiva de sua superação a fim de que o objetivo do processo educativo seja alcançado - a aprendizagem.

O recorte que sentimos necessidade de fazer entre o ensino presencial e a educação a distância para abordar o papel da linguagem, oral ou escrita, como a principal ferramenta de interlocução e acompanhamento da aprendizagem; suscita que outra questão relevante é saber considerar os elementos comuns e peculiares em relação a: modalidade, sistema, instituição e turmas; no momento de analisarmos a existência do erro, sua complexidade e generalizações, bem como as possíveis maneiras de utilização dos erros, sejam individuais ou coletivos, em benefício dos alunos e do processo de ensino-aprendizagem.

Há que se destacar o fato de termos alcançado o objetivo de evidenciar os aspectos subjacentes aos erros individuais presentes no processo de ensino-aprendizagem institucionalizado através do entrelaçamento de teorias já existentes e o dialogo com três componentes curriculares, tendo em consideração tanto a especificidade de cada uma como os elementos comuns existentes entre elas.

A discussão feita em três essas áreas de conhecimento - Biologia, Matemática e Física nos aponta para a universalidade do tema que pode ser tratado dentro da especificidade de cada componente curricular, sendo interessante fazê-lo, pois o processo de escolarização exige êxito em todas as disciplinas; torna-se um grande avanço o entendimento e a busca de superação dos erros nas disciplinas em destaques, porém, tornar-se-á muito pouco se não abranger as demais, visto que falar de educação é muito mais do que um conjunto de disciplina; no entanto, o processo educativo só terá cumprido seu papel com o êxito do aluno em cada uma e, consequentemente, em todas as disciplinas. 


\section{Referências}

ALMOULOUD, Ag Saddo. A Geometria na escola básica: que espaço e forma têm hoje?

<http://www.ufpel.tche.br/ufpel.Tche.br/clmd/bvm/detalhe_livro.php?ld_livro=395>. Acessado em 18 de jan.2006.

BASTOS, F. (1992). O conceito de célula viva entre os alunos de segundo grau. Em Aberto, ano 11, $55,63-69$.

BACHELARD, Gaston. A formação do espírito científico: contribuições para a psicanálise do conhecimento. Tradução: Estela dos Santos Abreu. Rio de Janeiro: Contraponto, 1996.

BONDÍA, Jorge Larrosa. Notas sobre a experiência e o saber de experiência. Revista Brasileira de Educação, No 19, Jan - Abr, p. 20 - 28, 2002.

BROUSSEAU, G. Fondements et al. methodoes de la didactique des mathématiques. In BITTENCOURT, Jane. Obstáculos Epistemológicos e a pesquisa em Didática da Matemática. Revista Educação Matemática, v.6, ano 5, maio,1998.

BROUSSEAU, G. Les obstacles épistémologiques et les problèmes en mathématiques. In BITTENCOURT, Jane. Obstáculos Epistemológicos e a pesquisa em Didática da Matemática. Revista Educação Matemática, [S.L.], v. 6, ano 5, maio,1998.

CURY, Helena Noronha. Retrospectiva Histórica e Perspectivas atuais da Análise de Erros em Educação Matemática. Zetetiké. Campinas - S. P, v. 3, n. 4, p 39 - 50, 1995.

DE LA TORRE, S. Errores y currículo - Tratamiento didáctico de los errores en la enseñanza. In: PINTO, Neuza Bertoni. O erro como estratégia didática: Estudo do erro no ensino da matemática elementar. Campinas - SP: Papirus, 2000.

GÓMEZ, A. I. P. A cultura escolar na sociedade neoliberal. Porto Alegre: Art med. 2001.

GOTINO, J., BATANERO, C. \& FONT. Fundamentos de la enseñanza y aprendizaje de la matemática para maestro. Universidad de Granada. Distribución en internet: http// www.ugr.es/local/jgotino/edumat-maestro/. In: Pochulu, M. D. Análisis y categorización de errores en el aprendizaje de la matemática en alumnos que ingresan a la universidad. Revista Iberoamericana de Educación, 2005. Disponível em http://www.rieoei.org/ deloslectores/ 849Pochulu.pdf

GUSMÃO, Tânia Cristina Rocha Silva. Do erro construtivismo ao erro epistemológico: um Espaço Para as Emoções. Bolema, v. 13, n. 14, p. 51 - 65, 2000.

JAPIASSU, Hilton Ferreira. Introdução ao pensamento epistemológico. $7^{a}$ Ed. Rio de Janeiro: F. Alves, 1934

LUCKESI, Cipriano C. Avaliação da aprendizagem escolar. São Paulo: Cortez, 1995.

MARTINS, L.P. A História da Ciência e o ensino da Biologia. Ciência e Ensino. Jornal Semestral do gepCE. Unicamp. Dezembro, 1998.

MIRANDA, Werventon dos Santos. Erros e Obstáculos: Os conteúdos Matemáticos do Ensino Fundamental no Processo de Avaliação. Dissertação de Mestrado em Educação em Ciências e Matemáticas do Núcleo Pedagógico de Apoio ao Desenvolvimento Científico - NPADC da UNIVERSIDADE FEDERAL DO PARÁ. Defendido em fevereiro de 2007. 
MOYSÉS, Lucia. Aplicações de Vygotsky à educação matemática. Campinas - SP.: Papirus, 1997.

MORTIMER, E. F. (1996). Construtivismo, mudança conceitual e ensino de Ciências: para onde vamos? Investigações em Ensino de Ciências, 1(1), 20-39.

OLIVEIRA, Nanci de. Linguagem, comunicação e matemática. Revista Educação, v. 10, n. 10, p.129140, 2007.

PAIS, Luiz Carlos. Didática da Matemática: uma influência francesa. $1^{\text {a }}$ ed. Belo Horizonte: Autêntica, 2001.

PINTO, Neuza Bertoni. O erro como estratégia didática: Estudo do erro no ensino da matemática elementar. Campinas - SP: Papirus, 2000.

SILVEIRA, R. V. M. da. . Como os estudantes do ensino médio relacionam os conceitos de localização e organização do material genético? Dissertação de mestrado. São Paulo: Instituto de Biociências da Universidade de São Paulo, 2003. 